\title{
Adequação de demandas funcionais de atividades para a parti- cipação escolar de crianças com disfunções neuromotoras
}

\author{
Débora Morais Pereira* \\ Rita de Cássia Tibério Araúio**

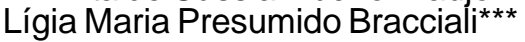

\section{Resumo}

A participação escolar é condição essencial para a construção do conhecimento, aprendizagem e desenvolvimento. Déficits neurológicos podem afetar a capacidade da criança para explorar o ambiente e se engajar em atividades típicas. Considerando a importância de se incentivar profissionais da área da educação a realizarem adaptações simples nas atividades escolares do dia-a-dia, este trabalho teve como objetivo adaptar, com materiais de baixo custo, recursos lúdicos e didáticos para crianças com distúrbios neuromotores. Foram objetos de estudo oito recursos adaptados prescritos e elaborados para três crianças com diagnóstico de paralisia cerebral: dominó, quebra-cabeça, jogo de memória, alfabeto móvel imantado, cruzadinha, boneco de esquema corporal, adaptação de lápis para escrita e pulseira de chumbada. A análise desses recursos ocorreu sob parâmetros do design convencional e das competências de manuseio, seguida pela identificação das condições limitantes da capacidade motora dos casos observados, indicação dos materiais utilizados na adaptação e possíveis finalidades. Este estudo oferece subsídios para a implementação de estratégias pedagógicas no atendimento do aluno com distúrbios neuromotores.

Palavras-chave: Educação Especial; Deficiência física; Recurso adaptado.

\section{Fitness of functional demands of activities for the school particitation of children with neuromotor dysfunction}

\section{Abstract}

The school participation is a prerequisite for the construction of knowledge, learning and development. Neurological deficits may affect child's ability to explore the environment and engage in typical activities. Considering the importance of encouraging professionals in the field of education to conduct simple adjustments in school activities of daily life, this study aimed to adapt, with low

\footnotetext{
* Aprimoranda do Programa de Aprimoramento Profissional de Terapia Ocupacional na Interface Saúde e Educação da Universidade Estadual Paulista Júlio de Mesquita Filho. Marília, São Paulo, Brasil.

** Professora Doutora do Departamento de Educação Especial da Universidade Estadual Paulista Júlio de Mesquita Filho. Marília, São Paulo, Brasil.

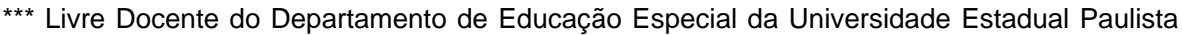
Júlio de Mesquita Filho. Marília, São Paulo, Brasil.
} 
cost materials, resources of entertainment and educational for children with neuromotor disorders. It was objects of this study eight resources prescribed and designed for three children diagnosed with cerebral palsy: domino, puzzle, memory game, moving magnetized alphabet, crossword, doll body scheme, adaptation of pencils for writing and bracelet sinker. The analysis of these resources occurred in the parameters of conventional design and management skills, followed by identifying the limiting conditions of the motor skills of the cases observed, indicating the materials used in the adaptation and possible uses. This study provides subsidy for implementation of teaching strategies in the care of students with neuromotor disorders.

Keywords: Special Education; Physical desabilities; Adapted resource.

\section{Introdução}

Em nossa sociedade é esperado das crianças a realização de uma variedade de Atividades de Vida Diária (AVD), de brincadeiras e de tarefas escolares. Contudo, déficits neurológicos podem afetar a capacidade da criança para explorar o ambiente e se engajar em atividades típicas, comprometendo também, segundo Erhardt e Merrill (2002), a recepção e o processamento das informações sensoriais, o controle motor, a coordenação da movimentação distal, a integração visuo-motora e as habilidades cognitivas. Diante desse quadro de disfunção ocupacional, a diminuição das oportunidades de interação com o meio constitui um fator agravante do atraso ou de possíveis distúrbios do desenvolvimento de habilidades motoras.

Um programa de ensino adequado à capacidade exploratória de indivíduo com disfunção neuromotora pode minimizar as implicações cognitivas das experiências sensoriais e perceptivas limitadas (OLIVEIRA, GAROTTI, SÁ, 2008).

A participação escolar é condição essencial para a construção do conhecimento, aprendizagem e desenvolvimento, pois permite a aquisição de aptidões e competência, colabora para o relacionamento com as pessoas e a comunidade e para o encontro da finalidade e significado na vida (ABE, 2009).

Segundo Araújo e Galvão (2007) "existe uma diversidade de ações e de intervenções terapêuticas para crianças com desordens neuromotoras que vão ao encontro do restabelecimento ou favorecimento do desempenho e/ou do envolvimento em uma ocupação" (p. 334). Ainda segundo as autoras, no contexto escolar, as intervenções devem ser direcionadas para o posicionamento adequado da postura sentada, adaptações de objetos e utensílios de escrita e leitura, assim como para a indicação de softwares de computador.

A adaptação de recursos e estratégias na educação almeja atender às necessidades educacionais dos alunos com deficiência, possibilitando um ensi- 
no que respeite as características individuais dos mesmos, desenvolvendo seu potencial, sua interação, descoberta e compreensão do mundo (REGANHAN; MANZINI, 2009).

Para Galvão Filho (2009) "existe um número incontável de possibilidades de recursos simples e de baixo custo que podem e devem ser disponibilizados nas salas de aula inclusivas, conforme as necessidades específicas de cada aluno com necessidades educacionais especiais presente nessas salas [...]". $E$, segundo esse mesmo autor, a ausência de recursos pedagógicos na escola não está necessariamente vinculada à questão financeira, muitas vezes ocorre pelo desconhecimento da existência dos mesmos.

A disponibilização de alguns recursos e adaptações de baixo custo para determinados alunos com deficiência, que podem ser construídos pelos próprios professores, freqüentemente representa a diferença entre poder ou não estudar e aprender junto com seus colegas (GALVÃO FILHO, 2009). Rocha, Luiz e Zulian (2003) corroboram com essa idéia quando afirmam que pequenas soluções no cotidiano escolar contribuem para o processo de ensino e aprendizagem de forma coerente com os pressupostos da inclusão escolar.

Segundo Galvão Filho (2009), além das adaptações relacionadas aos utensílios escolares, produtos que visam facilitar as AVD e as atividades de lazer da pessoa com deficiência, em muitos casos, podem ter relação direta com as atividades educacionais, uma vez que estas compõem situações da rotina escolar.

A indicação de adaptações justifica-se com base nos determinantes individuais e ambientais da aprendizagem e do desenvolvimento, tendo-se que "a aprendizagem ocorre a partir de um processo de construção diária, pelo qual todo o indivíduo passa, independente de suas condições motoras e/ou cognitivas" (OLIVEIRA, GAROTTI, SÁ, 2008, p. 246) e que o

Brincar é uma das atividades fundamentais para o desenvolvimento e a educação da criança. Brincando, a criança tem oportunidade de exercitar suas funções psico-sociais, experimentar desafios, investigar e conhecer o mundo de maneira natural e espontânea. (BRACCIALI; MANZINI; REGANHAN, 2004, p. 38).

Segundo Ferland (2006), o brincar é uma modalidade terapêutica em si; coloca à prova os mecanismos cognitivos da criança que brinca; utiliza músculos; promove emoções e interação com os outros e favorece o desenvolvimento das atitudes e das habilidades. Segundo a mesma autora, as limitações físicas podem dificultar a expressão da criança na brincadeira, seu processo de socialização e desenvolvimento cognitivo.

Desde que haja um ambiente que considere as incapacidades e possibilidades de uma criança com deficiência é possível propiciar o seu desenvol- 
vimento, apesar das limitações que possam decorrer da deficiência na estrutura e função corporal (MOTTA; TAKATORI, 2001). Diante de prejuízo de desempenho no ambiente escolar, a prescrição de adaptação em recursos auxiliares de ensino ocorre visando à adequação de demandas funcionais para facilitar o acesso de crianças com deficiência às atividades cotidianas que compõem esse contexto. Del-Masso e Araújo (2008, p. 72) referem que a adaptação de recursos "favorece a inclusão e está, por conseguinte, diretamente relacionada à acessibilidade tendo como referência fundamental o entorno".

As adaptações dão, portanto, oportunidade para a participação ativa da criança no processo de ensino e aprendizagem, sendo a sua prescrição fundamental no contexto escolar.

Considerando a importância de se incentivar profissionais da área da educação a realizarem adaptações simples nas atividades escolares do dia-adia, este trabalho teve como objetivo adaptar, com materiais de baixo custo, recursos lúdicos e didáticos para crianças com distúrbios neuromotores, destacando os materiais utilizados e possibilidades de uso.

\section{Método}

Foram objetos de estudo deste trabalho os recursos adaptados que foram elaborados e utilizados no tratamento terapêutico ocupacional de crianças com distúrbio neuromotores atendidas pelo Programa de Aprimoramento Profissional de Terapia Ocupacional em um centro de reabilitação no interior de São Paulo.

A indicação de recursos para adaptação teve como parâmetro as exigências funcionais do currículo escolar em situações específicas de recreação e de atividades pedagógicas e também as necessidades funcionais da criança nos domínios de seus interesses e competências cognitivas.

As prescrições de adaptação ocorreram com base na necessidade identificada durante os atendimentos de terapia ocupacional realizados no período de março a dezembro de 2009. No total, foram confeccionados oito recursos, sendo eles dominó, quebra-cabeça, jogo de memória, alfabeto móvel imantado, cruzadinha, bonecos de esquema corporal, adaptação de lápis para escrita e pulseira de chumbada.

Os recursos foram adaptados especificamente para três crianças com distúrbios neuromotores, sendo duas com diagnóstico médico de paralisia cerebral discinética ou extrapiramidal ${ }^{1}$ e uma com diagnóstico de paralisia cerebral atáxica, ${ }^{2}$ com idade variando de sete a oito anos.

Para a adaptação dos recursos foram utilizados os seguintes materiais: placa de ferro imantada, imã, isopor, fita adesiva, adesivos infantis (stickers), chum- 
bada, fio de silicone, miçangas coloridas, boneco "agarradinho", papel A4, papel A3, caneta hidrográfica, revólver e refil de cola quente.

Para análise e discussão dos resultados teve-se como parâmetro os elementos que compõem a análise de atividade com base em dados da literatura científica.

O projeto foi aprovado pelo Comitê de Ética e pelo Conselho Diretor do Centro de Estudos da Educação e da Saúde (CEES), segundo o parecer número 1959/2009.

\section{Resultados e discussão}

A análise e discussão da prescrição dos recursos adaptados foram realizadas englobando as demandas funcionais da atividade sem adaptação (design convencional) e com adaptação. Este é um procedimento contemplado na análise da atividade, que, segundo Silva (2007), é necessária para avaliar como o cliente realiza uma determinada tarefa, visando à identificação de quais aspectos precisam ser adaptados para a melhora do desempenho.

De acordo com Paiva e Braccialli (2009, p. 308), "alunos com paralisia cerebral podem apresentar algumas dificuldades relacionadas à preensão de objetos em virtude dos comprometimentos motores apresentados". Ainda segundo as autoras, considerando essa dificuldade, a adaptação das características físicas dos recursos utilizados, como formato, peso, tamanho e textura é importante para o sucesso desses alunos em atividades que envolvam movimentos com os membros superiores.

Para Santos (1998) alguns dos motivos de se adaptar as atividades para crianças com paralisia cerebral reside na facilitação da coordenação manual, diminuição do gasto energético na execução das atividades e facilitação das AVD.

A seguir serão apresentados os recursos adaptados iniciando com uma breve análise da atividade sob parâmetros do design convencional e das competências de manuseio esperadas para a faixa etária, seguida pela identificação das condições limitantes da capacidade motora, indicação dos materiais utilizados na adaptação e possíveis finalidades dos recursos.

Levando em conta os diagnósticos destacados neste estudo, os recursos foram distribuídos em dois grupos de prescrição. Os recursos dominó, quebra-cabeça, jogo de memória, alfabeto móvel imantado, cruzadinha e boneco de esquema corporal foram adaptados para as crianças com paralisia cerebral do tipo discinética. A adaptação de lápis para escrita e a pulseira de chumbada e foram prescritas e confeccionadas para a criança com paralisia cerebral do tipo atáxica. 
Dominó (figuras 1 e 2)

Análise da atividade com design convencional:

- Aspectos motores: coordenação para alcançar as peças, preensão (usualmente pinça polpa-polpa), coordenação para levar a peça até o local correto e soltura das mesmas.

- Aspectos cognitivos: conceito de igualdade, percepção visual para identificar a peça correta e orientação espacial.

\section{Condições limitantes da criança com PC do tipo discinética para executar} esta atividade:

• coordenação motora voluntária deficitária;

- dificuldade para realizar preensão polpa-a-polpa;

- elevado gasto energético.

\section{Materiais utilizados na adaptação:}

- imã e placa de ferro imantada: para que a peça possa ser deslizada na superfície da placa, diminuindo a demanda de coordenação motora e melhorando o desempenho da criança na atividade;

-isopor: para aumentar o tamanho e espessura da peça de maneira a propiciar uma preensão "em gancho";

- fita adesiva para tornar a peça lisa e lavável;

•impresso de dominó disponível no mercado, prezando sempre a aparência do recurso.

\section{Possíveis finalidades:}

- atividades lúdicas educativas tanto em sala de aula quanto em momentos de recreação externa;

• interação social entre alunos com e sem deficiência; 


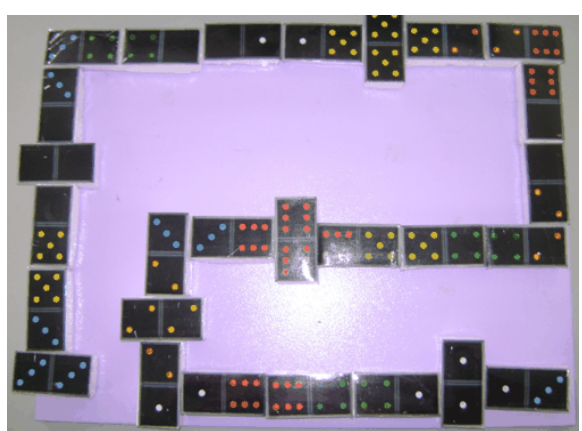

Figura 1: dominó adaptado

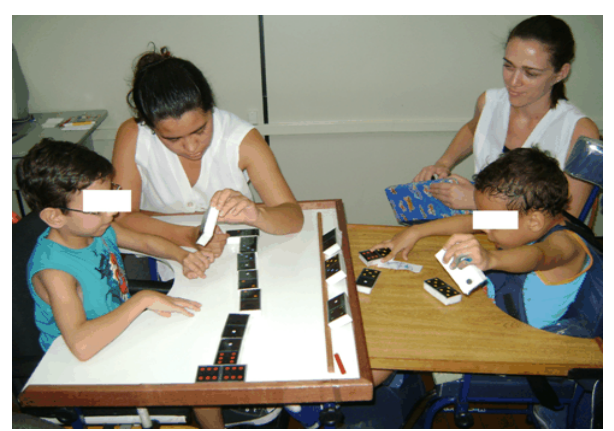

Figura 2: atividade em grupo com dominó adaptado

Segundo Pereira (1998) a coordenação visuo-motora de pessoas com paralisia cerebral atetóide (discinética) é deficiente devido à ausência de movimentação independente do olho/cabeça e constante mudança de posição da cabeça, o que por sua vez também afetam o equilíbrio e a estabilidade do corpo e membros. Ainda segundo a autora, o uso de pinça polpa-a-polpa (realizado entre as polpas do polegar e do indicador) não deve ser esperado da criança atetóide. Os padrões comuns de preensão são "em gancho" (não há participação do polegar) ou palmar mal-elaborada.

Estudo realizado por Paiva (2009) com crianças com paralisia cerebral do tipo espástica ${ }^{3}$ identificou que a textura lisa do recurso adaptado diminuiu o tempo despendido para a realização da tarefa de encaixe, e melhorou o desempenho dos participantes com relação à trajetória do movimento executado durante essa tarefa.

Quebra-cabeça (figuras 3 e 4)

Análise da atividade com design convencional:

- Aspectos motores: coordenação para alcançar as peças, preensão (usualmente pinça polpa-a-polpa), coordenação para levar a peça até o local correto e soltura e encaixe das mesmas.

- Aspectos cognitivos: noção da parte e do todo, percepção visual para identificar a semelhança entre as peças e orientação espacial.

\section{Condições limitantes da criança com PC do tipo discinética para execu- tar esta atividade:}

- coordenação motora voluntária deficitária;

- dificuldade para realizar preensão polpa-a-polpa;

- dificuldade pra realizar encaixe das peças;

- elevado gasto energético. 


\section{Materiais utilizados na adaptação:}

- imã e placa de ferro imantada: para que a peça possa ser deslizada na superfície da placa, diminuindo a demanda de coordenação motora e melhorando o desempenho da criança na atividade;

-isopor: para aumentar o tamanho e espessura da peça de maneira a propiciar uma preensão "em gancho";

- peças com laterais retas para facilitar o encaixe;

- fita adesiva para tornar a peça lisa e lavável;

-impresso do desenho selecionado de acordo com o interesse da criança.

\section{Possíveis finalidades:}

- atividades lúdicas educativas tanto em sala de aula quanto em momentos de recreação;

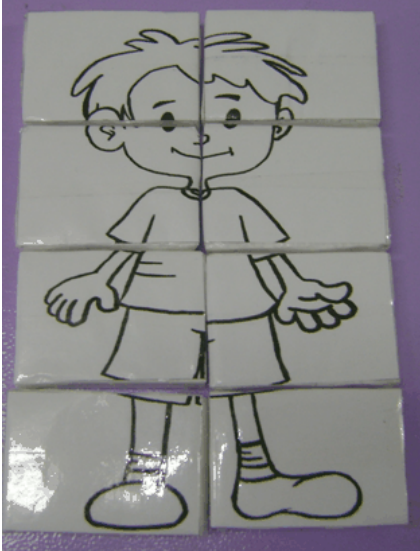

Figura 3: quebra-cabeça menino

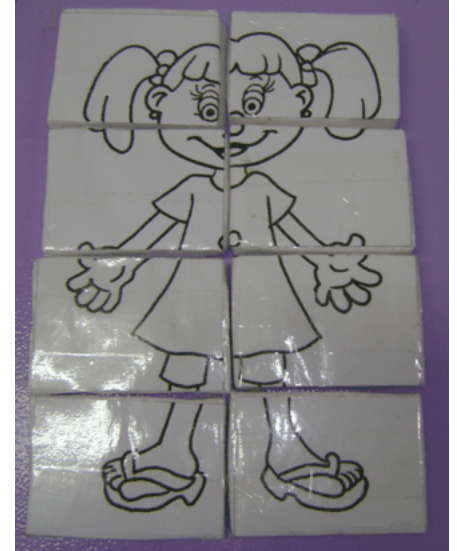

Figura 4: quebra-cabeça menina

Jogo de Memória (figuras 5 e 6 )

Análise da atividade com design convencional:

- Aspectos motores: coordenação para alcançar as peças, preensão (usualmente pinça polpa-a-polpa), movimento de pronação e supinação de antebraço, coordenação para levar a peça até o local correto e soltura das mesmas. ção.

- Aspectos cognitivos: conceito de igualdade, memorização e aten- 


\section{Condições limitantes da criança com PC do tipo discinética para execu- tar esta atividade:}

• coordenação motora voluntária deficitária;

- dificuldade para realizar preensão polpa-a-polpa;

- dificuldade para realizar movimento de pronação e supinação de antebraço

- elevado gasto energético.

\section{Materiais utilizados na adaptação:}

- dois imãs na superfície com desenho e um imã na superfície sem desenho e placa de ferro imantada: para que o participante possa virar a peça com mais facilidade (depois de verificar qual é a peça, a criança pode jogar a mesma sobre a placa imantada que a peça tenderá a cair com a superfície do desenho para baixo por estar mais pesada). Essa estratégia supre a demanda de prono e supinação do antebraço exigida pela atividade no design convencional.

-isopor: para aumentar o tamanho e espessura da peça de maneira a propiciar uma preensão "em gancho";

- fita adesiva para tornar a peça lisa e lavável;

- stickes com o personagem escolhido pelo paciente;

\section{Possíveis finalidades:}

- atividades lúdicas educativas tanto em sala de aula quanto em momentos de recreação;

• interação social entre alunos com e sem deficiência;

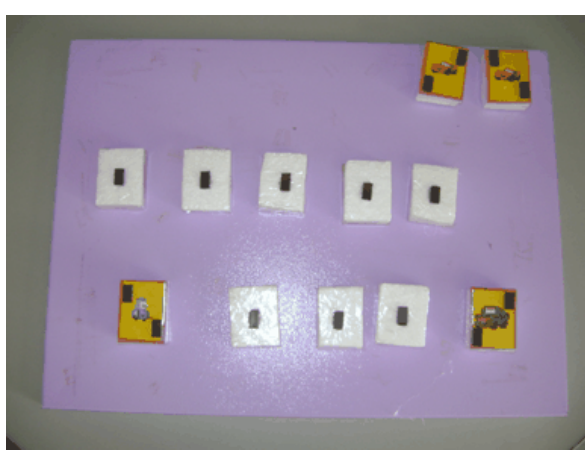

Figura 5: jogo de memória (visão geral)

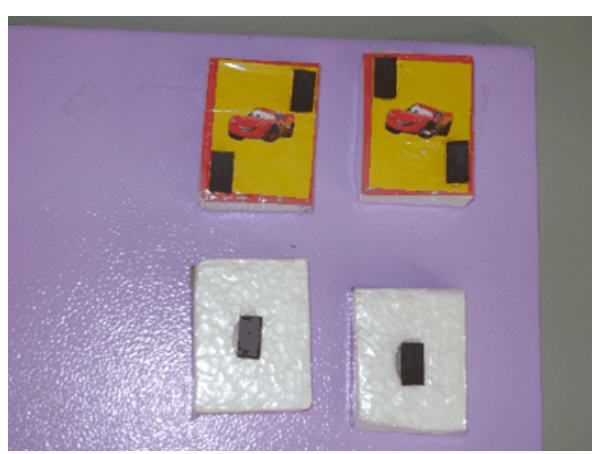

Figura 6: jogo de memória "carros" (visão aproximada) 


\section{Boneco de Esquema Corporal (figura 7)}

Análise da atividade com design convencional:

- Aspectos motores: coordenação para alcançar as peças, preensão (usualmente pinça polpa-a-polpa), coordenação para levar a peça até o local correto e soltura das mesmas.

- Aspectos cognitivos: esquema corporal, nomeação das partes do corpo, orientação espacial e percepção visual.

\section{Condições limitantes da criança com PC do tipo discinética para executar esta atividade:}

• coordenação motora voluntária deficitária;

- dificuldade para realizar preensão polpa-a-polpa;

- elevado gasto energético.

Materiais utilizados na adaptação:

- imã e placa de ferro imantada: para que a peça possa ser deslizada na superfície da placa, diminuindo a demanda de coordenação motora e melhorando o desempenho da criança na atividade;

-isopor: para aumentar o tamanho e espessura da peça de maneira a propiciar uma preensão "em gancho";

- fita adesiva para tornar a peça lisa e lavável;

-desenho do boneco decorado em EVA para prezar pela aparência do recurso

\section{Possíveis finalidades:}

- atividades lúdicas com propósitos e contextualização específicos dependendo da etapa de ensino; 


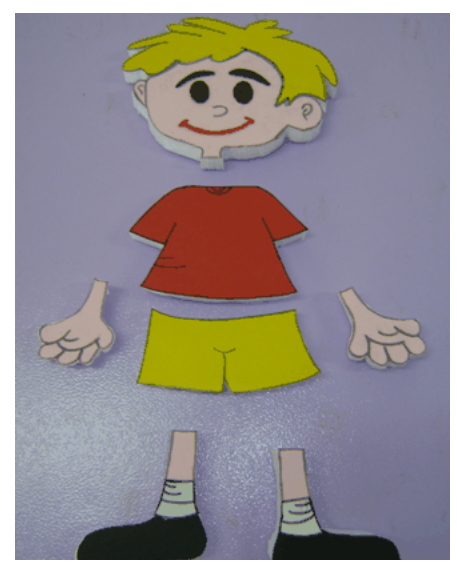

Figura 7: boneco de esquema corporal

Os recursos acima citados referem-se a adaptações em jogos que podem ser usados em ambiente escolar, pois segundo Braccialli, Manzini e Reganhan (2004):

\begin{abstract}
ao brincar e jogar, diversos aspectos são estimulados, desenvolvidos ou aperfeiçoados: a criatividade; a memorização; a cooperação e solidariedade; a concentração; a linguagem; a motivação; a aquisição de conceitos; a motricidade; a capacidade de discriminar, julgar, analisar, tomar decisões e aceitar críticas; a competitividade; a socialização; a confiança em si e em suas possibilidades, o respeito às regras e o controle emocional (p. 38).
\end{abstract}

Alfabeto móvel imantado (figuras 8 e 9)

Análise da atividade com design convencional (escrita):

- Aspectos motores: preensão para segurar o lápis ou caneta (usualmente preensão em três pontos), destreza para realizar e coordenar movimentos delicados (movimentos variados dos dedos);

- Aspectos cognitivos: capacidade de realizar cópia, percepção visual e memorização das letras (entre outros).

\title{
Condições limitantes da criança com PC do tipo discinética para execu- tar esta atividade:
}

- coordenação motora voluntária deficitária;

- destreza de movimentos deficiente;

- dificuldade para realizar preensão de três pontos para segurar o lápis; 
- elevado gasto energético.

\section{Materiais utilizados na adaptação:}

- imã e placa de ferro imantada: para que a peça possa ser deslizada na superfície da placa, diminuindo a demanda de coordenação motora e melhorando o desempenho da criança na atividade;

-isopor: para aumentar o tamanho e espessura da peça de maneira a propiciar uma preensão "em gancho";

- fita adesiva para tornar a peça lisa e lavável;

- impresso das letras em computar ou compradas prontas.

Possíveis finalidades:

- atividades lúdicas educativas;

- recurso para introdução da escrita

• interação social (meio de comunicação);

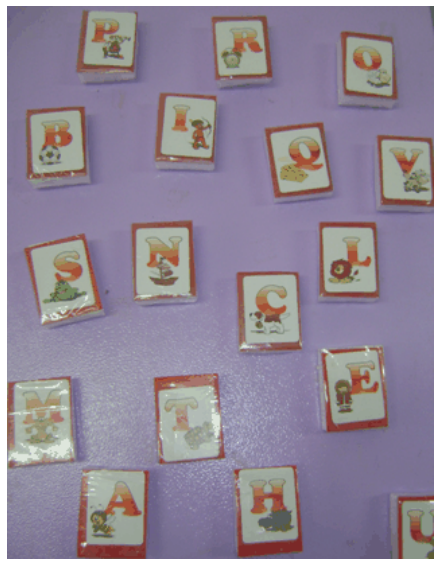

Figura 8: alfabeto móvel com impresso de letras comprado

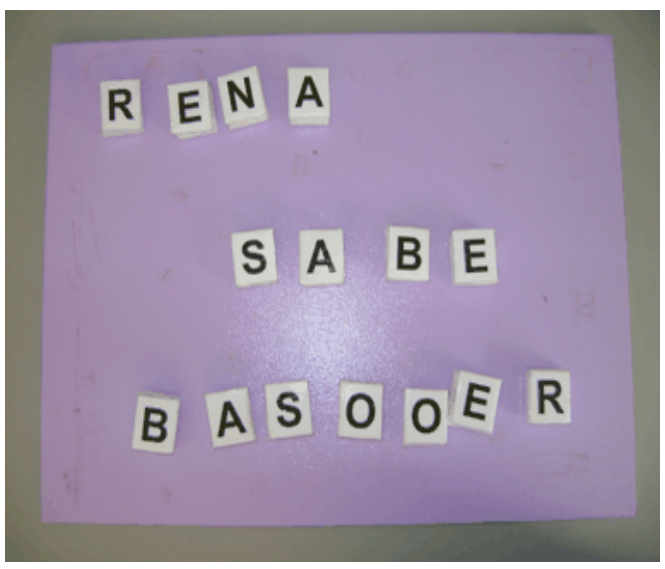

Figura 9: alfabeto móvel com letras impressas

Segundo Santos(1998): "Se a escrita manual não é possível mesmo com o uso de adaptações, deve-se pensar em alternativas de comunicação como tábua de letras, computador, máquina de escrever, ponteira de cabeça; placas imantadas, pranchas inclinadas, outros" (p. 283). 
Cruzadinha (figura 10)

Análise da atividade com design convencional (escrita):

- Aspectos motores: preensão para segurar o lápis ou caneta (usualmente preensão de três pontos), destreza para realizar e coordenar movimentos delicados (movimentos variados dos dedos)

- Aspectos cognitivos: capacidade para desenhar as letras, percepção visual, memorização de palavras (entre outros).

Condições limitantes da criança com PC do tipo discinética para executar esta atividade:

- coordenação motora voluntária deficitária;

- destreza de movimentos deficiente;

pis;

- dificuldade para realizar preensão de três pontos para segurar o lá-

•elevado gasto energético.

Materiais utilizados na adaptação:

- as letras imantadas já confeccionadas (figuras 10 e 11)

- papel A3 com determinação dos espaços onde as letras deverão ser colocadas e distribuição das figuras da palavra a ser escrita;

- fita adesiva para fixar o papel A3 sobre a placa imantada.

\section{Possíveis finalidades:}

- atividades lúdicas educativas;

• exploração da escrita em situação de jogo;

- interação social entre alunos com e sem deficiência. 


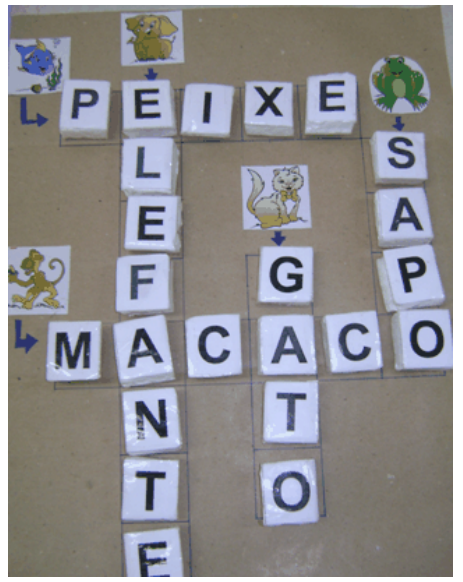

Figura 10: cruzadinha com alfabeto móvel

A seguir serão descritos os recursos adaptados que foram prescritos e confeccionados para uma criança com paralisia cerebral do tipo atáxica. Segundo Pereira (1998) a coordenação motora é um fator invariavelmente alterado no atáxico, o que compromete, entre outras atividades, a escrita. Ainda conforme a autora, a escrita destes pacientes é "incoordenada e sem ritmo, com dificuldades para seguir linhas pontilhadas, respeitar limites (espaço), contornar e preencher figuras" (p.249); o tremor intencional aumenta a incoordenação motora, dificultando a preensão do lápis/caneta (nos padrões convencionais). Entre as sugestões de adaptações para a escrita do atáxico a autora cita: a fixação do caderno, adaptação do lápis com engrossador para dar maior firmeza na preensão e pesos para diminuir os tremores intencionais.

A fim de se evitar a fadiga muscular em indivíduos com encefalopatia, o cálculo de resistência máxima (RM) é um parâmetro norteador na definição de pesos.

Em relação ao peso de objetos utilizados em estudos com crianças com paralisia cerebral, Paiva (2007) apresentou pesquisas que trabalharam com pesos que variaram de 25 a $720 \mathrm{~g}$. No estudo de Audi (2006) a definição do peso ocorreu individualmente por meio do cálculo de resistência máxima (RM) partindo do emprego de um peso com o qual o indivíduo conseguisse realizar o movimento em amplitude total, por dez repetições, e gradualmente, o peso foi aumentado até o limite de resistência máxima.

Mendoza e colaboradores (2003, apud AUDI, 2006), após estudarem um grupo de meninos com paralisia cerebral, concluíram que os treinamentos de força e de potência deveriam ser entre $50 \%$ e $60 \%$ da carga máxima.

Nesta presente pesquisa, o desempenho na realização da atividade constituiu o parâmetro norteador da adição de peso, uma vez que não se pretendeu o fortalecimento muscular, mas, sim, a funcionalidade. O peso foi definido a 
partir da observação da qualidade da ação da criança e também mediante a conclusão da atividade. Iniciou-se a adaptação do objeto com a adição de $5 \mathrm{~g}$, utilizando-se múltiplos dessa mesma medida para o aumento gradual de peso. A definição do peso teve como referência o limite mínimo de adição a partir do qual observou-se a estabilidade da qualidade da ação nos dois acréscimos subseqüentes.

\section{Adaptação de lápis para escrita (figuras 11 e 12)}

Análise da atividade com design convencional :

-Aspectos motores: preensão para segurar o lápis ou caneta (usualmente preensão em três pontos), destreza para realizar e coordenar movimentos delicados (movimentos variados dos dedos);

-Aspectos cognitivos: capacidade de realizar cópia, percepção visual e memorização das letras (entre outros).

\section{Condições limitantes da criança com PC do tipo atáxico para executar esta atividade:}

• incoordenação motora;

pis;

- dificuldade para realizar preensão de três pontos para segurar o lá-

- tremor intencional.

Materiais utilizados na adaptação:

- lápis comum;

- agarradinho com imã para tornar o lápis mais pesado (adição de 20g), diminuindo o tremor intencional, mantendo a aparência do recurso interessante para a criança;

- cordão de chumbada (adição de $5 \mathrm{~g}$ ) para prender o agarradinho ao lápis e aumentar o peso do material escolar contribuindo para a diminuição do tremor intencional.

\section{Possíveis finalidades:}

- atividades lúdicas educativas;

- recurso para introdução da escrita. 


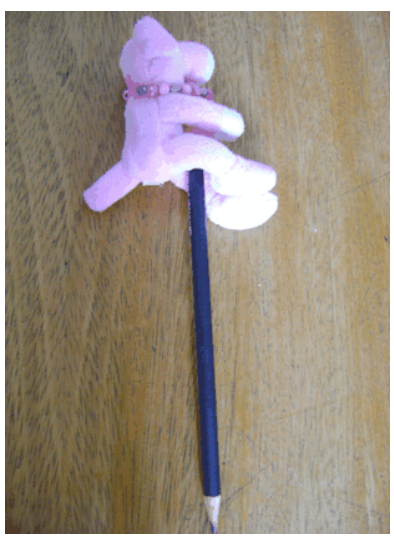

Figura 11: lápis adaptado com agarradinho

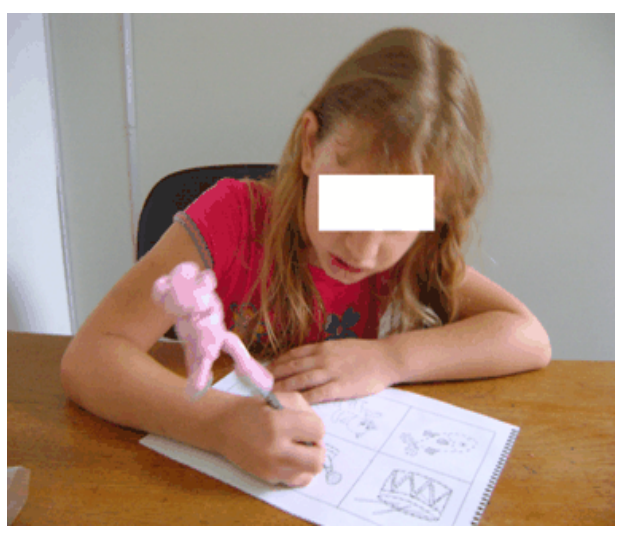

Figura 12: criança com Paralisia Cerebral Atáxica utilizando o lápis adaptado

Segundo Santos (1998) a adição de peso nos recursos deve ser realizada de maneira individual e graduada. Neste caso, o peso foi adicionado ao lápis de maneira a diminuir o tremor intencional, mas tomando cuidado para não deixá-lo muito pesado para esta criança em questão, pois com a hipotonia usualmente encontrada em crianças com este tipo de seqüela o excesso de peso pode tornar a atividade cansativa.

A adaptação do lápis com o agarradinho e a pulseira de chumbada foi pensada considerando a praticidade de troca deste acessório. O lápis poderia ter sido engrossado de diversas maneiras para facilitar a preensão, mas, a pedido da criança, o design do recurso não foi alterado.

Um recurso bastante interessante para diminuir os tremores de ação bem como movimentos involuntários que tanto prejudicam a realização de diversas atividades escolares e de vida diária é a pulseira de chumbo ou chumbada.

Estudo realizado por Audi (2006) com o objetivo de analisar o comportamento motor de membros superiores, no movimento de apontar um alvo, com e sem o uso de peso, em indivíduos que apresentavam movimentos involuntários nos membros superiores demonstrou que o uso da pulseira com peso tornou o movimento mais preciso, com melhor direção e deslocamento escalar menor, favorecendo a realização de um movimento mais adequado e funcional.

Pulseira de chumbada (figura 13) esta atividade:

Condições limitantes da criança com PC do tipo atáxico para executar

• incoordenação motora;

- tremor intencional (movimento involuntário). 


\section{Materiais utilizados na adaptação:}

- fio de silicone;

- miçangas coloridas (adição de 10g);

- chumbada (adição de $30 \mathrm{~g}$ ) com furo do mesmo tamanho das miçangas.

\section{Possíveis finalidades:}

-melhora da performance em atividades educativas, lúdicas e de vida diária que exijam coordenação motora.

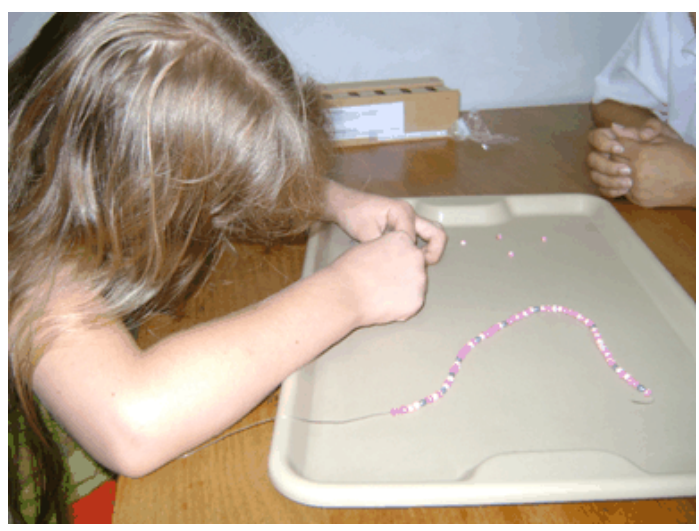

Figura 13: criança confeccionando sua própria pulseira com chumbada.

Assim como no lápis adaptado foi tomado cuidado para que o peso adicionado à pulseira não elevasse o gasto energético para a movimentação do membro superior.

O mais interessante da confecção da pulseira de chumbada foi que a adaptação foi realizada pela própria criança. Segundo relato da mãe, professora e da criança houve a aceitação e interesse pelo uso do recurso. A motivação para a aceitação e uso do recurso pode ter sido influenciada pelo envolvimento da criança na sua confecção.

Segundo Cavalcanti e Galvão (2007) a confecção de adaptações deve ser realizada de acordo com as necessidades dos clientes e sua possibilidade de aquisição, visando sempre à ampliação da capacidade de envolvimento e participação do indivíduo em ocupações ou tarefas. Ainda conforme as autoras, ao elaborar ou adquirir uma adaptação deve-se prezar a estética, a segurança e a simplicidade; deve-se também envolver o cliente na seleção e no treino do uso dos equipamentos para a aceitação e usabilidade dos mesmos.

Silva (2007) afirma que "a adaptação de uma atividade deve se ajustar à necessidade específica do cliente, ser simples o suficiente para que a tarefa 
possa ser executada, manter o valor e o significado da atividade e centrar-se na própria atividade, e não no movimento puro que está sendo realizado" (p. 121). Relata ainda que "o propósito da graduação da atividade é melhorar a capacidade do cliente para executar as tarefas em limites toleráveis, com o objetivo de alcançar o seu maior nível de funcionalidade" (p. 123).

Adaptações nos recursos pedagógicos que vão ao encontro das necessidades específicas dos alunos que delas precisarem podem colaborar para evitar alguns dos fatores que funcionam como barreiras para o aprendizado do aluno: frustração no desempenho da atividade pedagógica, insucesso e desmotivação (PAIVA, 2007).

Segundo Schirmer e colaboradoes (2007) os recursos adaptados para a aprendizagem de alunos com deficiência beneficiam a todos os alunos, pois despertam o interesse de todos, tornam a aula mais atraente e significativa.

\section{Conclusão}

As prescrições de adaptação mostradas neste estudo ocorreram com base nas necessidades identificadas durante atendimentos ambulatoriais de terapia ocupacional, no entanto podemos verificar que todos eles podem ser utilizados no contexto escolar.

Apesar dos recursos terem sido adaptados para crianças com Paralisia Cerebral, muitas das adaptações confeccionadas podem ser utilizadas por crianças com deficiência física de diferentes etiologias, mas com dificuldades semelhantes.

Para prescrever e elaborar as adaptações é necessário avaliar as demandas das atividades, identificar as dificuldades que a criança com deficiência apresenta para realizar a atividade com design convencional e buscar, na literatura, formas sugeridas para a adaptação da demanda funcional para a qual a criança apresenta dificuldade. Partindo desse raciocínio, inúmeros recursos utilizados em sala de aula podem ser adaptados para ampliar e maximizar situações favoráveis ao ensino do aluno cujo desempenho se encontra prejudicado por dificuldades motoras.

Este estudo mostrou que muitas das adaptações podem ser realizadas com materiais de baixo-custo, os quais, na maioria das vezes, estão disponíveis para o professor em sala de aula. 


\section{Referências}

$A B E, P$. B. Desempenho funcional nas atividades de rotina escolar de alunos com necessidades educacionais especiais na perspectiva do professor. 2009. 100f. Dissertação (Mestrado em Educação) - Faculdade de Filosofia e Ciências, Universidade Estadual Paulista “Júlio de Mesquita Filho, Marília, 2009.

ARAÚJO, A. E.; GALVÃO, C. Desordens neuromotoras. In: CAVALCANTI, A.; GALVÃO, C. Terapia Ocupacional: fundamentação \& prática. Rio de Janeiro: Guanabara Koogan, 2007.

AUDI, M. Estudo comparativo do comportamento motor de membro superior em encefalopatas que fazem uso de pulseira estabilizadora. 2006. 112 f. Dissertação (Mestrado em Educação) - Faculdade de Filosofia e Ciências, Universidade Estadual Paulista, Marília, 2006.

BRACCIALLI, L. M. P.; MANZINI, E. J.; REGANHAN, W. G. Contribuição de um programa de jogos e brincadeiras adaptados para a estimulação de habilidades motoras em alunos com deficiência física. Temas sobre desenvolvimento, $v$. 13, n. 77, p. 37-46, 2004.

CAVALCANTI, A.; GALVÃO, C. Adaptação ambiental e doméstica. In: CAVALCANTI, A.; GALVÃO, C. (Org.). Terapia ocupacional: fundamentação e prática. Rio de Janeiro: Guanabara Koogan, 2007.

DEL-MASSO, M. C. S.; ARAÚJO, R. C. T. Necessidades educacionais especiais: questões relacionadas ao desempenho do aluno. In: OLIVEIRA, A.A.S.; OMOTE, S.; GIROTO, C. R. M. (Org.). Inclusão escolar: as contribuições da Educação Especial. São Paulo: Fundepe, 2008.

ERHARDT, R. P.; MERRILL, S.C. Disfunção neurológica em crianças. In: NEISTADT, M. E.; CREPEAU, E.B. Willard \& Spackman Terapia Ocupacional. 3. ed. Rio de Janeiro: Guanabara Koogan, 2002.

FERLAND, F. O modelo lúdico: o brincar, a criança com deficiência e a terapia ocupacional. 3. ed. Roca: São Paulo, 2006.

GALVÃO FILHO, T. A. Tecnologia assistiva para uma escola inclusiva: apropriação, demandas e perspectivas. 2009. 346f. Tese (Doutorado em Educação) - Faculdade de Educação, Universidade Federal da Bahia, Salvador, 2009.

GAUZZI, L. D. V.; FONSECA, L. F. Classificação da paralisia cerebral. In: LIMA, C. L. A.; FONSECA, L.F. Paralisia cerebral: neurología, ortopedia, classificação. Rio de Janeiro: Guanabara Koogan, 2004.

MOTTA, M. P.; TAKATORI, M.A assistência em terapia ocupacional sob a perspectiva do desenvolvimento da criança. In: DE CARLO, M. M. R. P.; BARTALOTTI, C. C. (Org.). Terapia ocupacional no Brasil: fundamentos e perspectivas. 2. ed. São Paulo: Plexus, 2001. 
OLIVEIRA, A. I. A.; GAROTTI, M. F.; SÁ, N. M. C. M. Tecnologia de ensino e tecnologia assistiva no ensino de crianças com paralisia cerebral. Ciências \& Cognição, Cidade Universitária, v. 13, n. 3, p. 243-262, 2008.

PAIVA, P. C.; BRACCIALLI, L. M. P. Textura do recurso pedagógico e implicações em atividade de encaixe realizada por indivíduos com paralisia cerebral. Revista Brasileira de Educação Especial, v. 15, n. 2, p. 307-318, 2009.

PAIVA, P. C. Influência da textura do recurso pedagógico em atividades de encaixe realizada por alunos com paralisia cerebral. 2007.104 f Dissertação (Mestrado em Educação) - Faculdade de Filosofia e Ciências, Universidade Estadual Paulista, Marília, 2007.

PEREIRA, D. B. Terapia ocupacional em paralisia cerebral atetóide e atáxica. In: SOUZA, A. M. C.; FERRARETTO, I. (Org.). Paralisia cerebral: aspectos práticos. 2. ed. São Paulo: Memnon, 1998.

REGANHAN, W. G.; MANZINI, E. J. Percepção de professores do ensino regular sobre recursos e estratégias para o ensino de alunos com deficiência. Revista Educação Especial, Santa Maria, v. 22, n. 34, p. 127-138, 2009.

ROCHA, E. F.; LUIZ, A.; ZULIAN, M. A. R. Reflexões sobre as possíveis contribuições da terapia ocupacional nos processos de inclusão escolar. Revista de Terapia Ocupacional da Universidade de São Paulo, São Paulo, v. 14, n. 2, p. $72-78,2003$.

SANTOS, L. S. B. Adaptações em paralisia cerebral. In: SOUZA, A. M. C.; FERRARETTO, I. (Org.). Paralisia cerebral: aspectos práticos. 2. ed. São Paulo: Memnon, 1998.

SCHIRMER, C. R.; BROWNING, N.; BERSCH, R.; MACHADO, R. Formação continuada a distância de professores para o atendimento educacional especializado: deficiência física. Brasília: MEC, 2007.

SILVA, S. N. P. Análise de atividades. In: CAVALCANTI, A.; GALVÃO, C. Terapia ocupacional: fundamentação \& prática. Rio de Janeiro: Guanabara Koogan, 2007.

Correspondência

Débora Morais Pereira - Rua Vinte e Qutro de Dezembro, 3489. CEP 17507-030, Marília, São Paulo, Brasil.

E-mail: debora_terapi@yahoo.com.br

Recebido em 13 de abril de 2010

Aprovado em 23 de junho de 2010 